\title{
Angiotensin II Blockade and Aortic-Root Dilation in Marfan's Syndrome
}

\author{
Benjamin S. Brooke, M.D., Jennifer P. Habashi, M.D., Daniel P. Judge, M.D., \\ Nishant Patel, B.A., Bart Loeys, M.D., Ph.D., and Harry C. Dietz III, M.D.
}

\section{A B STRACT}

\section{BACKGROUND}

Progressive enlargement of the aortic root, leading to dissection, is the main cause of premature death in patients with Marfan's syndrome. Recent data from mouse models of Marfan's syndrome suggest that aortic-root enlargement is caused by excessive signaling by transforming growth factor $\beta$ (TGF- $\beta$ ) that can be mitigated by treatment with TGF- $\beta$ antagonists, including angiotensin II-receptor blockers (ARBs). We evaluated the clinical response to ARBs in pediatric patients with Marfan's syndrome who had severe aortic-root enlargement.

\section{METHODS}

We identified 18 pediatric patients with Marfan's syndrome who had been followed during 12 to 47 months of therapy with ARBs after other medical therapy had failed to prevent progressive aortic-root enlargement. The ARB was losartan in 17 patients and irbesartan in 1 patient. We evaluated the efficacy of ARB therapy by comparing the rates of change in aortic-root diameter before and after the initiation of treatment with ARBs.

\section{RESULTS}

The mean $( \pm S D)$ rate of change in aortic-root diameter decreased significantly from $3.54 \pm 2.87 \mathrm{~mm}$ per year during previous medical therapy to $0.46 \pm 0.62 \mathrm{~mm}$ per year during ARB therapy $(\mathrm{P}<0.001)$. The deviation of aortic-root enlargement from normal, as expressed by the rate of change in $\mathrm{z}$ scores, was reduced by a mean difference of $1.47 \mathrm{z}$ scores per year $(95 \%$ confidence interval, 0.70 to 2.24 ; $\mathrm{P}<0.001$ ) after the initiation of ARB therapy. The sinotubular junction, which is prone to dilation in Marfan's syndrome as well, also showed a reduced rate of change in diameter during ARB therapy $(\mathrm{P}<0.05)$, whereas the distal ascending aorta, which does not normally become dilated in Marfan's syndrome, was not affected by ARB therapy.

\section{CONCLUSIONS}

In a small cohort study, the use of ARB therapy in patients with Marfan's syndrome significantly slowed the rate of progressive aortic-root dilation. These findings require confirmation in a randomized trial.

From the McKusick-Nathans Institute of Genetic Medicine and the Howard Hughes Medical Institute (B.S.B., J.P.H., N.P., B.L., H.C.D.), the Department of Surgery (B.S.B.), and the Department of Medicine and Cardiology (D.P.J.), Johns Hopkins University School of Medicine, Baltimore; and the Center for Medical Genetics, Ghent University Hospital, Ghent, Belgium (B.L.). Address reprint requests to Dr. Dietz at the McKusick-Nathans Institute of Genetic Medicine, Johns Hopkins University School of Medicine, 539 Broadway Research Bldg., 733 N. Broadway, Baltimore, MD 21205, or at hdietz@jhmi.edu.

N Engl J Med 2008;358:2787-95.

Copyright (๑) 2008 Massachusetts Medical Society. 
M

ARFAN'S SYNDROME, AN AUTOSOMAL dominant connective-tissue disorder affecting approximately 1 in 5000 people, is caused by mutations in the gene encoding fibrillin-1 (FBN1). ${ }^{1,2}$ FBN1 mutations lead to defects in multiple organ systems, of which the most lifethreatening is progressive enlargement and dissection of the aortic root. ${ }^{3,4}$ Current medical management of Marfan's syndrome is focused on serial cardiac-imaging studies and the use of pharmacologic agents to reduce hemodynamic stress on the aortic wall. Pharmacologic treatment often involves the use of beta-adrenergic-receptor antagonists (beta-blockers), although other agents, such as angiotensin-converting-enzyme (ACE) inhibitors and calcium-channel blockers, have been used in patients who have unacceptable adverse events or no response to beta-blockers. ${ }^{5-7}$

Studies in a mouse model of Marfan's syndrome have shown that a deficiency of fibrillin-1 in the extracellular matrix leads to excessive signaling by transforming growth factor $\beta$ (TGF- $\beta$ ), an event that probably contributes to the pathogenesis of multiple phenotypic features of Marfan's syndrome, including progressive enlargement of the aortic root. ${ }^{8-11}$ These genetically engineered mice, in which the pathologic changes in the aortic root closely mimic those seen in humans, were subsequently used to demonstrate the therapeutic benefit of treatment with TGF- $\beta$ antagonists in vivo. The development of pathologic changes in the aortic wall and the progressive dilation of the aortic root were attenuated or prevented by systemic treatment with a TGF- $\beta$-neutralizing antibody or the angiotensin II-receptor blocker (ARB) losartan, an antihypertensive medication known to inhibit TGF- $\beta$ signaling. ${ }^{10,12}$ In comparison, mutant mice treated with the beta-blocker propranolol continued to show substantial aortic-wall pathologic changes and had only a moderate reduction in the rate of aortic-root dilation. These findings led us to hypothesize that treatment with ARBs might be effective for the prevention of aortic-root enlargement and associated cardiovascular pathologic changes in patients with Marfan's syndrome.

METHODS

STUDY DESIGN AND PATIENTS

We retrospectively reviewed the records of all pediatric patients treated in the medical genetics clinic of Johns Hopkins Hospital who met the
Ghent diagnostic criteria ${ }^{13}$ for Marfan's syndrome and who were followed prospectively from October 1996 through November 2007. The diagnosis of Marfan's syndrome was confirmed in each patient after exclusion of other known congenital aneurysm syndromes on the basis of distinguishing phenotypic features, molecular mutation analysis, or both (see the Supplementary Appendix, available with the full text of this article at www.nejm.org). This retrospective study was approved by the institutional review board of Johns Hopkins University, which waived the requirement for informed consent.

We identified a cohort of 18 patients with Marfan's syndrome, 14 months to 16 years of age, who had begun ARB therapy between November 2003 and May 2006 and had continued to receive the therapy for at least 1 year of follow-up. An additional patient was identified who was prescribed an $A R B$, but this patient was excluded from the analysis after we found documented periods of nonadherence to therapy. The decision to initiate ARB therapy in these patients was made on clinical grounds during routine visits. Although no formal inclusion criteria were applied, factors that influenced the decision to prescribe ARBs included evidence of a rapid rate of change in aortic-root diameter despite other medical therapy, including beta-blockers with or without ACE inhibitors (11 patients); an aortic-root diameter of at least $4.0 \mathrm{~cm}$, approaching the threshold for surgical intervention (6 patients); and unacceptable adverse events associated with conventional pharmacologic agents (1 patient). Details of therapy before the initiation of ARB treatment are provided in the Supplementary Appendix.

We identified 65 additional pediatric patients with Marfan's syndrome who had undergone echocardiography at least three times at Johns Hopkins Hospital during the study period, had not had aortic-root surgery, and had not received ARB therapy. All patients in this cohort had received beta-blockers according to a dosing regimen similar to that used in the recipients of ARBs before the initiation of ARB therapy.

\section{THERAPY WITH ARBS}

Therapy was initiated in 17 patients with the ARB losartan (Cozaar, Merck) at an initial oral dose of $0.6 \mathrm{mg}$ per kilogram of body weight per day; therapy with ACE inhibitors or calcium-channel blockers was discontinued at this time. The patients 
were assessed for adverse events at this starting dose over a 3-week period before the dose was gradually increased to a sustained dose of $1.4 \mathrm{mg}$ per kilogram per day. Therapy was initiated in one additional patient with the ARB irbesartan (Avapro, Bristol-Myers Squibb) at an initial dose of $1.4 \mathrm{mg}$ per kilogram per day and a final dose of $2.0 \mathrm{mg}$ per kilogram per day. The blood urea nitrogen and creatinine levels (i.e., renal function) and electrolyte levels were assessed after the patients had received ARB therapy for 3 months. Beta-blocker therapy was not decreased or discontinued unless the patient had adverse events in association with both medications (see the Supplementary Appendix).

\section{ECHOCARDIOGRAPHY}

Two-dimensional transthoracic echocardiograms were obtained every 3 to 12 months as part of routine clinical care, with the use of transducers appropriate for the patient's size. Complete orthogonal sweeps from the subxiphoid, apical, parasternal, and suprasternal-notch windows were obtained during each study. Measurements of maximal aortic diameter were taken at the aortic annulus, sinotubular junction, ascending thoracic aorta, and aortic root at the sinuses of Valsalva with the use of a parasternal long-axis view. The maximal diameter of these segments was determined by measuring from internal edge to internal edge of the aortic wall during ventricular systole on an axis perpendicular to the path of blood flow.

All echocardiograms obtained at Johns Hopkins Hospital were read by attending cardiologists who were not involved in the study and who were unaware of the patient's treatment status. A subgroup of studies was performed on selected patients, and the results were interpreted at other institutions. The majority of the echocardiograms were reviewed at Johns Hopkins to ensure standardization of measurement practices.

A $z$ score was calculated for each echocardiographic measurement with the use of standard algorithms. The $\mathrm{z}$ score represented the standard deviation from the mean aortic diameter normalized for the patient's body-surface area and age. ${ }^{14}$ In addition, measurements of heart rate, blood pressure, height, and weight were obtained at the time of each echocardiogram. Measurements of height and weight were used to calculate the bodymass index and were converted into $\mathrm{z}$ scores normalized for sex and age.

\section{STATISTICAL ANALYSIS}

The Wilcoxon signed-rank test was used to compare the rates of change in aortic diameter before and after the initiation of ARB therapy in individual patients. The one-sample proportion test (sign test) was used to test for a consistent decrease in the rate of change in aortic-root diameter after the initiation of ARB therapy, with a null hypothesis of equal proportions. Linear regression models were fitted with the use of generalized estimating equations ${ }^{15}$ with a breakpoint to compare the rates of aortic enlargement before and after the initiation of ARB therapy, after adjustment for age and sex. The last model takes into account the correlation between repeated measures within individual patients. The Mann-Whitney U test was used to compare the changes in absolute and normalized aortic-root diameter between patients treated with ARBs and those treated with betablockers alone. Two-sided P values of less than 0.05 were considered to indicate statistical significance for all statistical tests and models. Stata statistical software, version 9.0, was used for all analyses.

\section{RESULTS}

\section{CHARACTERISTICS OF PATIENTS RECEIVING} ARB THERAPY

Demographic data, diagnostic criteria, and treatment information for the 18 pediatric patients receiving ARB therapy are given in Table 1 (and in Table 1 in the Supplementary Appendix). All patients had evidence of severe aortic-root enlargement, with a mean $( \pm S D)$ aortic-root diameter of $3.67 \pm 0.53 \mathrm{~cm}$ and a mean aortic-root-diameter $z$ score of $7.21 \pm 2.69$ at the time ARB therapy was initiated. The median duration of treatment before the initiation of ARB therapy was 48.6 months, with a median of seven echocardiograms per patient. The age at initiation of ARB therapy ranged from 14 months to 16 years. All patients were receiving the maximal weight-based dose within 6 months after the initiation of therapy. The patients were followed for a median of 26.1 months while receiving ARB therapy and had a median of five echocardiograms during that period.

At the time of data analysis, two patients, both of whom had severe aortic-root enlargement at the time of initiation of ARB therapy $(4.2 \mathrm{~cm}$ in one and $4.4 \mathrm{~cm}$ in the other), had undergone previously planned prophylactic aortic-root replacement when their aortic-root diameter reached approxi- 


\begin{tabular}{|c|c|}
\hline Variable & Value \\
\hline \multicolumn{2}{|l|}{ Age at initiation of $A R B-y r$} \\
\hline Median & 6.5 \\
\hline Range & $1-16$ \\
\hline Male sex — no. (\%) & $9(50)$ \\
\hline \multicolumn{2}{|l|}{ Race - no. (\%)† } \\
\hline White & $17(94)$ \\
\hline Black & $1(6)$ \\
\hline Aortic-root diameter at initiation of $A R B-c m$ & $3.67 \pm 0.53$ \\
\hline Aortic-root-diameter $z$ score at initiation of ARB & $7.21 \pm 2.69$ \\
\hline \multicolumn{2}{|l|}{ Previous treatment - no. (\%) } \\
\hline Beta-blocker alone & $12(67)$ \\
\hline Beta-blocker plus ACE inhibitor & $4(22)$ \\
\hline Beta-blocker plus calcium-channel blocker & $2(11)$ \\
\hline \multicolumn{2}{|l|}{ Previous treatment dose $-\mathrm{mg} / \mathrm{kg} /$ day } \\
\hline Beta-blocker & $1.83 \pm 0.38$ \\
\hline ACE inhibitor & $0.97 \pm 0.27$ \\
\hline Calcium-channel blocker & $4.12 \pm 1.04$ \\
\hline \multicolumn{2}{|l|}{ No. of echocardiograms per patient } \\
\hline \multicolumn{2}{|l|}{ Before initiation of ARB } \\
\hline Median & 7 \\
\hline Range & $3-15$ \\
\hline \multicolumn{2}{|l|}{ After initiation of ARB } \\
\hline Median & 5 \\
\hline Range & $2-10$ \\
\hline \multicolumn{2}{|l|}{ Duration of treatment - mo } \\
\hline \multicolumn{2}{|l|}{ Before initiation of $A R B$} \\
\hline Median & 48.6 \\
\hline Range & 12-104 \\
\hline \multicolumn{2}{|l|}{ After initiation of ARB } \\
\hline Median & 26.1 \\
\hline Range & $12-47$ \\
\hline
\end{tabular}

* Plus-minus values are means \pm SD. ACE denotes angiotensin-converting enzyme, and ARB angiotensin II-receptor blocker.

$\uparrow$ Race was self-assessed by the patient or parent.

mately $4.5 \mathrm{~cm}$. A third patient required mitral-valve repair because of valve insufficiency and left ventricular dysfunction. The data for these three patients were censored at the time of surgery.

\section{SIDE EFFECTS}

There were no significant changes in mean heart rate, mean systolic blood pressure, or mean dia- stolic blood pressure after the initiation of ARB therapy, as compared with the previous period when the patients were receiving beta-blockers, ACE inhibitors, or calcium-channel blockers (Table 2). Laboratory indicators of renal function were normal 3 months after the initiation of ARB therapy in all patients: the median blood urea nitrogen level was $15 \mathrm{mg}$ per deciliter $(5.4 \mathrm{mmol}$ per liter) (range, 7 to $25 \mathrm{mg}$ per deciliter [ 2.5 to $8.9 \mathrm{mmol}$ per liter]), and the median serum creatinine level was $0.5 \mathrm{mg}$ per deciliter $(44.2 \mu \mathrm{mol}$ per liter) (range, 0.3 to $0.8 \mathrm{mg}$ per deciliter [26.5 to $70.7 \mu \mathrm{mol}$ per liter]). No adverse events or side effects were documented among patients while they were receiving ARB therapy.

\section{BODY HEIGHT AND WEIGHT DURING ARB THERAPY}

There was a decline in the rate of change of increase in body height after the initiation of ARB therapy, with significant decreases in height velocity and in height-velocity $z$ scores, as compared with previous growth rates (see Table 2 in the Supplementary Appendix). No significant changes were found in the rate of change in body-weight measurements. This finding might be attributable, at least in part, to a reduction in linear growth and age-dependent fluctuations in the rate of change in body-mass index.

\section{AORTIC-ROOT DILATION DURING ARB THERAPY}

The mean rate of change in aortic-root diameter in patients before the initiation of ARB therapy was $3.54 \pm 2.87 \mathrm{~mm}$ per year. After the initiation of ARB therapy, this rate decreased to $0.46 \pm 0.62 \mathrm{~mm}$ per year, which represented a clinically and statistically significant difference in aortic dilatation $(\mathrm{P}<0.001)$ (Table 3). The mean and median rates of increase in aortic-root diameter were decreased by factors of approximately 8 and 11, respectively (Fig. 1A and Table 3). Similarly, the mean rate of change in aortic-root-diameter $z$ scores was $0.97 \pm 1.55$ per year before ARB therapy and decreased to $-0.50 \pm 0.43$ per year after the initiation of ARB therapy $(\mathrm{P}<0.001)$ (Table 3 and Fig. 1B). The $z$ score takes into account differences in age and body-surface area among patients and thus provides a measure that controls for the effects of these variables during follow-up. ${ }^{14}$

Regression modeling with the use of generalized estimating equations, after adjustment for age and sex, showed that the initiation of ARB therapy was independently associated with an estimated 


\begin{tabular}{|c|c|c|c|c|c|}
\hline \multirow[t]{2}{*}{ Measurement } & \multicolumn{2}{|c|}{ Before ARB Therapy } & \multicolumn{2}{|c|}{ After Initiation of ARB Therapy } & \multirow[t]{2}{*}{ P Value } \\
\hline & Median & Mean & Median & Mean & \\
\hline Heart rate (beats/min) & 79 & $81.3 \pm 13.0$ & 77 & $79.0 \pm 14.9$ & 0.11 \\
\hline Systolic blood pressure ( $\mathrm{mm} \mathrm{Hg}$ ) & 98 & $97.1 \pm 9.9$ & 98 & $97.9 \pm 11.0$ & 0.62 \\
\hline Diastolic blood pressure $(\mathrm{mm} \mathrm{Hg})$ & 59 & $58.3 \pm 6.0$ & 57 & $57.6 \pm 7.1$ & 0.67 \\
\hline
\end{tabular}

* Plus-minus values are means \pm SD. All hemodynamic measurements were taken at the time of the echocardiograms. ARB denotes angiotensin II-receptor blocker.

$\dagger P$ values for the differences in medians were calculated with the use of the Wilcoxon signed-rank test.

Table 3. Comparison of Annual Rates of Change in Aortic-Root Diameter and z Scores in Patients with Severe Marfan's Syndrome before and after Initiation of ARB Therapy and in Patients with Mild Marfan's Syndrome Receiving Beta-Blockers Alone.*

\begin{tabular}{|c|c|c|c|c|c|c|c|c|}
\hline \multirow[t]{3}{*}{ Variable } & \multicolumn{4}{|c|}{$\begin{array}{l}\text { Severe Marfan's Syndrome } \\
\qquad(\mathrm{N}=18)\end{array}$} & \multicolumn{4}{|c|}{$\begin{array}{l}\text { Mild Marfan's Syndrome } \\
\qquad(\mathrm{N}=65)\end{array}$} \\
\hline & \multicolumn{2}{|c|}{ Before ARB Therapy } & \multicolumn{2}{|c|}{$\begin{array}{l}\text { After Initiation } \\
\text { of ARB Therapy }\end{array}$} & \multirow[t]{2}{*}{ P Value $†$} & \multicolumn{2}{|c|}{$\begin{array}{l}\text { After Initiation of Therapy } \\
\text { with Beta-Blockers }\end{array}$} & \multirow[t]{2}{*}{ P Valuetr } \\
\hline & median & mean & median & mean & & median & mean & \\
\hline \multicolumn{9}{|l|}{ Aortic-root-diameter z score } \\
\hline Cohort average $\rrbracket$ & 6.7 & $6.52 \pm 2.43$ & NA & NA & & 3.0 & $3.25 \pm 1.52$ & $<0.001$ \\
\hline Last measurement & 7.2 & $7.21 \pm 2.69$ & 6.3 & $6.44 \pm 2.43$ & $<0.001$ & NA & NA & \\
\hline \multicolumn{9}{|l|}{ Change in aortic-root diameter } \\
\hline Absolute change (mm/yr) & 3.3 & $3.54 \pm 2.87$ & 0.3 & $0.46 \pm 0.62$ & $<0.001$ & 1.3 & $1.71 \pm 1.24$ & $<0.001$ \\
\hline Normalized change (z scores/yr) & 1.0 & $0.97 \pm 1.55$ & -0.5 & $-0.50 \pm 0.43$ & $<0.001$ & 0.1 & $0.24 \pm 0.50$ & $<0.001$ \\
\hline
\end{tabular}

* Plus-minus values are means \pm SD. Aortic diameters were measured during echocardiography and converted into rates of enlargement expressed as millimeters per year. The z scores were calculated from aortic-root diameters normalized for age and body-surface area. ARB denotes angiotensin II-receptor blocker, and NA not applicable.

$\dagger P$ values for the comparison of median rates of change in aortic-root diameter before and after the initiation of ARB therapy were calculated with the use of the Wilcoxon signed-rank test.

$\downarrow$ P values for the comparison of median cohort $z$ scores and rates of change in aortic-root diameter between patients with severe and mild Marfan's syndrome were calculated with the use of the Mann-Whitney $U$ test.

$\int$ The mean and median z scores were calculated from all echocardiograms obtained before the initiation of ARB therapy for patients with severe Marfan's syndrome or from all echocardiograms obtained during childhood for patients with mild Marfan's syndrome.

q The mean and median $\mathrm{z}$ scores were calculated from aortic-root diameters measured at the last echocardiogram obtained before the initiation of ARB therapy and at the most recent echocardiogram obtained during ARB therapy.

decrease in the rate of change in aortic-root diameter of $2.75 \mathrm{~mm}$ per year ( $95 \%$ confidence interval [CI], 1.65 to $3.84 \mathrm{~mm}$ per year; $\mathrm{P}<0.001)$ and an estimated decrease of 1.27 aortic-root-diameter $\mathrm{z}$ scores per year (95\% CI, 0.57 to $1.97 ; \mathrm{P}<0.001)$. The rate of change in aortic-root diameter was reduced among all patients after initiation of ARB therapy $(\mathrm{P}<0.001)$ (Fig. $2 \mathrm{~A}$, and Table 1 in the Supplementary Appendix), including the single patient treated with irbesartan (Fig. 2B).

The sinotubular junction, an aortic segment that is also prone to dilation in patients with severe Marfan's syndrome, also benefited from ARB therapy. The mean rate of change in absolute si- notubular-junction diameter was $2.02 \pm 1.13 \mathrm{~mm}$ per year before the initiation of ARB therapy and was reduced to $0.70 \pm 1.01 \mathrm{~mm}$ per year during $A R B$ therapy $(\mathrm{P}<0.05)$ (Table 4 and Fig. $1 \mathrm{~A})$. The normalized rate of sinotubular-junction enlargement decreased from $0.43 \pm 0.57 \mathrm{z}$ score per year during previous therapy to $-0.24 \pm 0.44 \mathrm{z}$ score per year during ARB therapy $(\mathrm{P}<0.05)$ (Table 4 and Fig. 1B). In comparison, more distal segments of the ascending aorta past the sinotubular junction, which are not generally affected by pathologic dilatation in Marfan's syndrome, showed no change in growth measurements after the initiation of ARB therapy. Both the mean rate of change in as- 


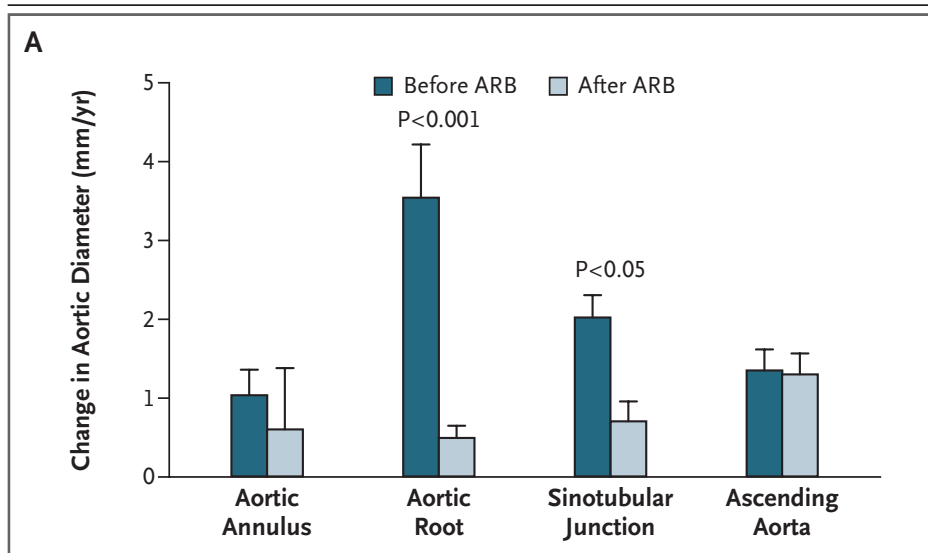

B

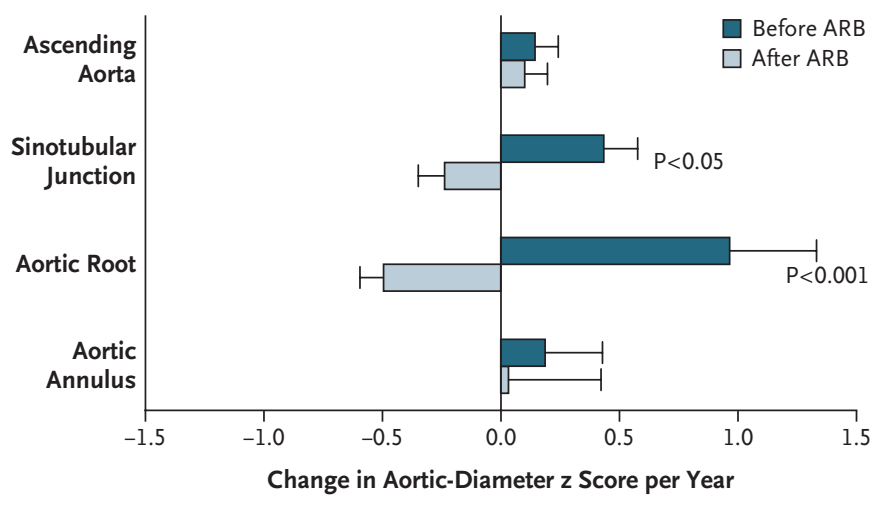

Figure 1. Mean Annual Rate of Change in Absolute and Normalized Aortic Diameters before and after Initiation of Therapy with an Angiotensin IIReceptor Blocker (ARB).

Panel A shows the rate of change in absolute aortic diameter, and Panel B shows the rate of change in aortic-diameter $z$ scores for four aortic segments that were measured over time in patients with severe Marfan's syndrome. All rates are expressed as means, with error bars representing standard errors. P values were calculated with the use of the Wilcoxon signed-rank test.
4 months to 19 years). Overall, this population had milder aortic-root disease, as evidenced by a reduced mean aortic-root-diameter $\mathrm{z}$ score for all echocardiograms obtained during childhood as compared with the mean $\mathrm{z}$ score of the cohort receiving ARB therapy (3.25 \pm 1.52 vs. $6.52 \pm 2.43$, $\mathrm{P}<0.001)$. The mean rates of change in aortic-root diameter $(1.71 \pm 1.24 \mathrm{~mm}$ per year) and in aorticroot-diameter $z$ score $(0.24 \pm 0.50$ per year $)$ in patients receiving beta-blockers alone were significantly higher than those in severely affected patients receiving ARB therapy $(\mathrm{P}<0.001$ for both comparisons) (Table 3).

DISCUSSION

The current study provides early evidence suggesting that the addition of losartan or another ARB to the traditional regimen used to treat aortic aneurysm in patients with Marfan's syndrome may be beneficial. The initiation of ARB therapy resulted in a significant reduction in the rate of change in aortic-root diameter as compared with beta-blocker therapy alone. The therapeutic effect extended to the sinotubular junction, a site also affected by Marfan's syndrome. In comparison, aortic segments not typically affected in Marfan's syndrome (e.g., the ascending aorta above the sinotubular junction) continued to show an annual rate of change in diameter that was appropriate for age and body size. Together, these findings suggest that ARBs do not arrest aortic growth but specifically reduce the pathologic rate of increase in the diameter of aortic segments that are already of sufficient size to accommodate the physiologic demands of the tissues for blood flow.

Losartan and irbesartan belong to the ARB class of antihypertensive medications that work by selectively blocking the angiotensin II type 1 (AT1) receptor within the renin-angiotensin-aldosterone system. ${ }^{16}$ In addition to antihypertensive and other effects, AT1-receptor blockade induces a clinically relevant decrease in TGF- $\beta$ signaling. ${ }^{12,17,18}$ This antagonism results in reduced plasma levels of free TGF- $\beta$, reduced tissue expression of TGF- $\beta$-responsive genes, and reduced levels of intracellular mediators within the TGF- $\beta$ signaling cascade, such as phosphorylated Smad2. In a prospective study of renal-transplant recipients, treatment with normal antihypertensive doses of losartan decreased plasma levels of TGF- $\beta$ by more than $50 \%$ within 2 weeks. ${ }^{18}$ 
The effects of angiotensin II are mediated by two receptors, the AT1 receptor and the angiotensin II type 2 (AT2) receptor. ${ }^{16}$ AT1-receptor signaling can increase the production of TGF- $\beta$ ligands and receptors, as well as activators such as thrombospondin-1. ${ }^{19}$ Cellular events observed in the tissues of persons with Marfan's syndrome, including proliferation of vascular smooth-muscle cells, fibrosis, and increased expression of matrix metalloproteinases 2 and 9 , are plausibly attributable to increased TGF- $\beta$ activity. ${ }^{8-10}$ In contrast, the AT2 receptor is thought to induce cellular effects opposite to those of the AT1 receptor, including antiproliferative and antiinflammatory effects that are beneficial in aortic-wall homeostasis. ${ }^{20}$

Given these mechanisms, the beneficial effects of ACE inhibitors and ARBs in this setting might be expected to differ. ACE inhibitors limit the production of angiotensin II and hence limit signaling through both the detrimental AT1-receptor pathway and the potentially protective AT2-receptor pathway and would not influence alternative mechanisms for angiotensin II production, such as the activity of mast-cell chymase. In contrast, ARBs cause selective blockade of the AT1 receptor, resulting in overactivation of the AT2-receptor pathway. ${ }^{10}$ In keeping with these mechanistic hypotheses, Daugherty and colleagues observed that AT1-receptor-blocking agents could prevent abdominal aortic aneurysms induced by the infusion of angiotensin II in apolipoprotein E-deficient mice, whereas selective AT2-receptor antagonists increased both the incidence and the severity of abdominal aneurysms in this model. ${ }^{21,22}$

On balance, however, it seems possible that the benefit of AT1-receptor antagonism achieved with ACE inhibitors could outweigh the potential negative influence of AT2-receptor blockade. A small, randomized, controlled trial of the ACE inhibitor perindopril as compared with placebo in adult patients with Marfan's syndrome who were receiving beta-blockers showed a reduced rate of change in aortic-root diameter that correlated with decreased circulating TGF- $\beta$ levels over a relatively short period of follow-up (24 weeks). ${ }^{23}$ Nevertheless, our recent observation of accelerated aorticroot enlargement in fibrillin-1-deficient mice after targeted disruption of the gene encoding the AT2 receptor further supports our hypothesis that selective AT1-receptor antagonists will provide superior protection in preventing aneurysmal dilation of the aortic root (unpublished data).

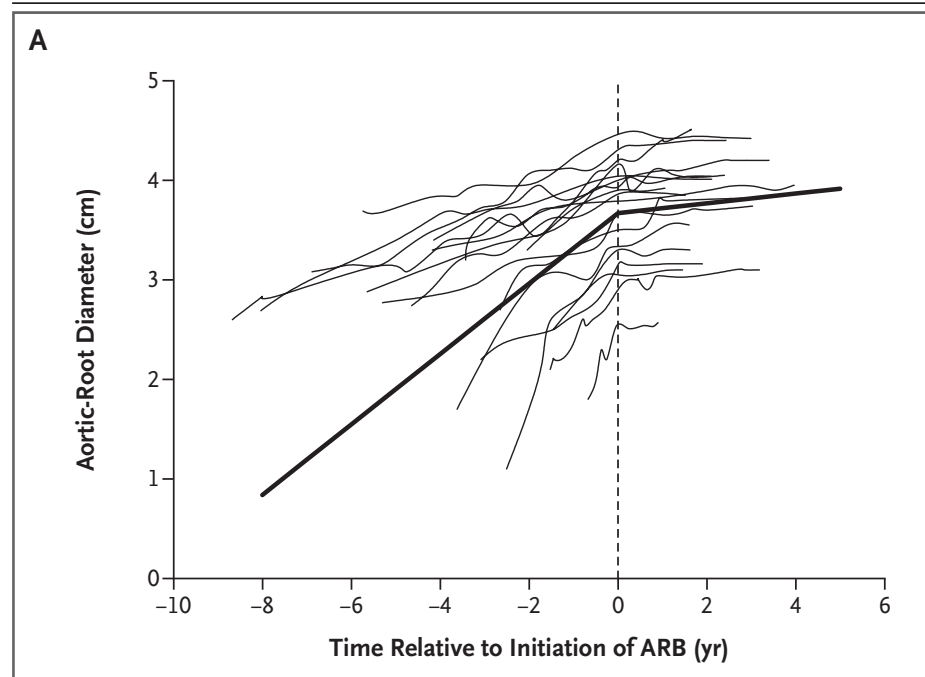

B

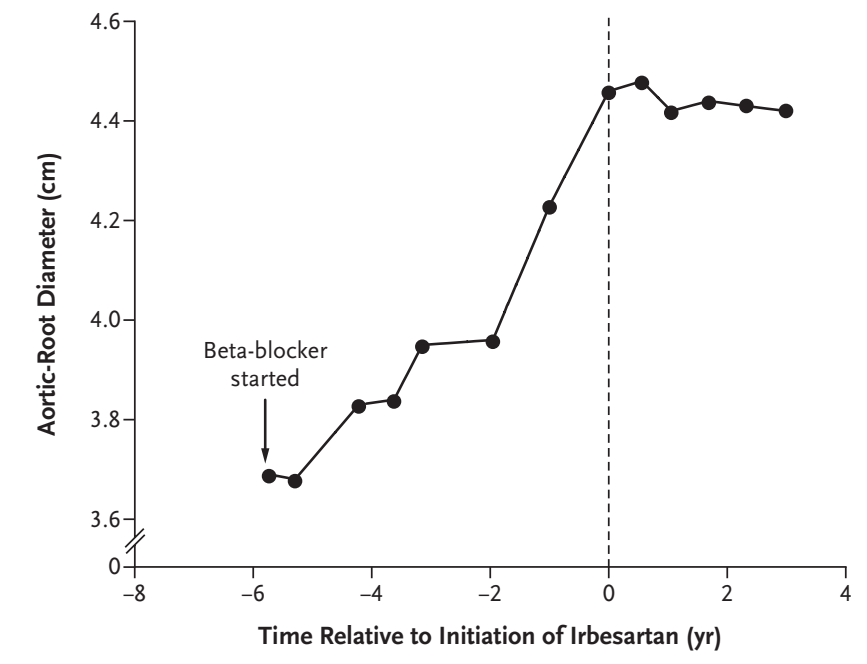

Figure 2. Change in Aortic-Root Diameter Standardized According to the Time of Initiation of Therapy with an Angiotensin II-Receptor Blocker (ARB).

Panel A represents the change over time in aortic-root diameter for each of the 18 patients in the analysis, with the solid trend line representing the overall mean change in aortic-root diameter before and after the initiation of ARB therapy. The time at which ARB therapy was started for all patients is standardized at year 0 and is represented by the vertical dashed line. The mean rate of change in aortic-root diameter was reduced among all 18 patients after $A R B$ therapy was initiated $(P<0.001$, sign test). Panel $B$ represents the change in aortic-root diameter in the one patient receiving irbesartan. The dashed line at year 0 represents the time of initiation of irbesartan and distinguishes the period during which beta-blocker therapy alone was administered from the period during which ARB therapy was added.

There are several limitations of our study. This was a nonrandomized, retrospective, observational study that evaluated only a small subgroup of pe- 


\begin{tabular}{|c|c|c|c|c|c|}
\hline \multirow[t]{2}{*}{ Aortic Segment } & \multicolumn{2}{|c|}{ Before ARB Therapy } & \multicolumn{2}{|c|}{$\begin{array}{l}\text { After Initiation } \\
\text { of ARB Therapy }\end{array}$} & \multirow[t]{2}{*}{ P Value $i$} \\
\hline & Median & Mean & Median & Mean & \\
\hline \multicolumn{6}{|l|}{ Aortic annulus } \\
\hline Absolute change (mm/yr) & 1.0 & $1.04 \pm 1.30$ & 1.1 & $0.60 \pm 0.31$ & 0.53 \\
\hline Normalized change (z scores/yr) & 0.2 & $0.19 \pm 0.97$ & 0.1 & $0.03 \pm 1.56$ & 0.18 \\
\hline \multicolumn{6}{|l|}{ Sinotubular junction } \\
\hline Absolute change (mm/yr) & 1.8 & $2.02 \pm 1.13$ & 0.5 & $0.70 \pm 1.01$ & $<0.05$ \\
\hline Normalized change (z scores/yr) & 0.3 & $0.43 \pm 0.57$ & -0.2 & $-0.24 \pm 0.44$ & $<0.05$ \\
\hline \multicolumn{6}{|l|}{ Ascending aorta } \\
\hline Absolute change (mm/yr) & 0.9 & $1.35 \pm 1.07$ & 0.9 & $1.30 \pm 1.06$ & 0.86 \\
\hline Normalized change (z scores/yr) & 0.1 & $0.14 \pm 0.39$ & 0.1 & $0.10 \pm 0.38$ & 0.57 \\
\hline
\end{tabular}

* Plus-minus values are means \pm SD. Aortic diameters were measured during echocardiography and converted into rates of enlargement expressed as millimeters per year. The $z$ scores were calculated from aortic-segment diameters normalized for age and body-surface area and converted into rates expressed as z scores per year. ARB denotes angiotensin II-receptor blocker.

$\uparrow P$ values for the differences in medians were calculated with the use of the Wilcoxon signed-rank test.

diatric patients with Marfan's syndrome who had evidence of severe aortic-root enlargement or rapid increase in aortic diameter. Selection bias may have resulted in the identification of patients who were more adherent to, and therefore more likely to have a response to, ARB therapy, although it could also be hypothesized that patients with established severe disease would be less likely to have a response to ARB therapy than would patients with milder disease. Although all patients in this study had a reduction in the rate of change of aortic-root diameter while receiving ARB therapy, there was variability in this therapeutic response (Fig. 2A, and Table 2 in the Supplementary Appendix) that may be correlated with the preexisting degree of pathologic change or other individually specific factors, such as genotype. This variability may alter the effectiveness of TGF- $\beta$ antagonism, which was not assessed in this study. It is also possible that up-regulation of AT1 receptors in response to chronic receptor antagonism may limit the long-term therapeutic effect of ARBs.

Despite the encouraging results of this observational study, equipoise is maintained regarding a role for ARB therapy in the treatment of patients with Marfan's syndrome; our findings must be confirmed by a prospective, randomized trial. A trial coordinated by the Pediatric Heart Network of the National Heart, Lung, and Blood Institute, comparing losartan with atenolol in patients with Marfan's syndrome, began enrolling patients in the winter of 2007, and we encourage all eligible patients to enroll in this trial. ${ }^{24,25}$ Until data from this trial are available, evidence for the potential efficacy of ARB therapy in this setting should be considered preliminary.

Supported by a K12 Mentored Clinical Research Scholars Grant (to Dr. Brooke), as well as research grants from the National Institutes of Health (to Dr. Dietz), the Howard Hughes Medical Institute (to Drs. Dietz and Patel), the William S. Smilow Center for Marfan Syndrome Research (to Dr. Dietz), the Dana and Albert "Cubby" Broccoli Center for Aortic Diseases (to Drs. Dietz and Judge), and the National Marfan Foundation (to Drs. Dietz, Habashi, and Patel). Dr. Loeys reports being a senior clinical investigator for the Fund for Scientific ResearchFlanders.

No potential conflict of interest relevant to this article was reported.

We thank Gretchen Oswald, Jennifer Leadroot, and numerous clinicians throughout the United States for their help in gathering patient data, as well as Dr. Steven Piantadosi and Dr. Richard Thompson for their assistance in designing and executing the statistical analyses of this study. 
REFERENCES

1. Dietz HC, Cutting GR, Pyeritz RE, et al. Marfan syndrome caused by a recurrent de novo missense mutation in the fibrillin gene. Nature 1991;352:337-9.

2. Dietz HC, Pyeritz RE. Mutations in the human gene for fibrillin-1 (FBN1) in the Marfan syndrome and related disorders. Hum Mol Genet 1995;4:1799-809.

3. Milewicz DM, Dietz HC, Miller DC. Treatment of aortic disease in patients with Marfan syndrome. Circulation 2005; 111(11):e150-e157.

4. Judge DP, Dietz HC. Marfan syndrome. Lancet 2005;366:1965-76.

5. Shores J, Berger KR, Murphy EA, Pyeritz RE. Progression of aortic dilatation and the benefit of long-term $\beta$-adrenergic blockade in Marfan's syndrome. $\mathrm{N}$ Engl J Med 1994;330:1335-41.

6. Rossi-Foulkes R, Roman MJ, Rosen SE, et al. Phenotypic features and impact of beta blocker or calcium antagonist therapy on aortic lumen size in the Marfan syndrome. Am J Cardiol 1999;83:13648.

7. Yetman AT, Bornemeier RA, McCrindle BW. Usefulness of enalapril versus propranolol or atenolol for prevention of aortic dilation in patients with the Marfan syndrome. Am J Cardiol 2005;95:1125-7.

8. Ng CM, Cheng A, Myers LA, et al. TGF- $\beta$-dependent pathogenesis of mitral valve prolapse in a mouse model of Marfan syndrome. J Clin Invest 2004;114: 1586-92.

9. Neptune ER, Frischmeyer PA, Arking DE, et al. Dysregulation of TGF- $\beta$ activation contributes to pathogenesis in Marfan syndrome. Nat Genet 2003;33:407-11. 10. Habashi JP, Judge DP, Holm TM, et al.
Losartan, an AT1 antagonist, prevents aortic aneurysm in a mouse model of Marfan syndrome. Science 2006;312:117-21.

11. Gelb BD. Marfan's syndrome and related disorders - more tightly connected than we thought. N Engl J Med 2006;355: 841-4.

12. Lavoie P, Robitaille G, Agharazii M, Ledbetter S, Lebel M, Larivière R. Neutralization of transforming growth factor-beta attenuates hypertension and prevents renal injury in uremic rats. J Hypertens 2005;23:1895-903.

13. De Paepe A, Devereux RB, Dietz HC, Hennekam RC, Pyeritz RE. Revised diagnostic criteria for the Marfan syndrome. Am J Med Genet 1996;62:417-26.

14. Sluysmans T, Colan SD. Theoretical and empirical derivation of cardiovascular allometric relationships in children. J Appl Physiol 2005;99:445-57.

15. Zeger SL, Liang KY. Longitudinal data analysis for discrete and continuous outcomes. Biometrics 1986;42:121-30.

16. Burnier M. Angiotensin II type 1 receptor blockers. Circulation 2001;103: 904-12.

17. Lim DS, Lutucuta S, Bachireddy P, et al. Angiotensin II blockade reverses myocardial fibrosis in a transgenic mouse model of human hypertrophic cardiomyopathy. Circulation 2001;103:789-91.

18. Campistol JM, Iñigo P, Larios S, Bes$\cos \mathrm{M}$, Oppenheimer F. Role of transforming growth factor-beta 1 in the progression of chronic allograft nephropathy. Nephrol Dial Transplant 2001;16:Suppl 1: 114-6.

19. Zhou Y, Poczatek MH, Berecek KH, Murphy-Ullrich JE. Thrombospondin 1 mediates angiotensin II induction of TGF-beta activation by cardiac and renal cells under both high and low glucose conditions. Biochem Biophys Res Commun 2006;339:633-41.

20. Wu L, Iwai $M$, Nakagami $\mathrm{H}$, et al. Roles of angiotensin II type 2 receptor stimulation associated with selective angiotensin II type 1 receptor blockade with valsartan in the improvement of inflammation-induced vascular injury. Circulation 2001;104:2716-21.

21. Daugherty A, Manning MW, Cassis LA. Antagonism of AT2 receptors augments angiotensin II-induced abdominal aortic aneurysms and atherosclerosis. $\mathrm{Br}$ J Pharmacol 2001;134:865-70.

22. Daugherty A, Rateri DL, Cassis LA. Role of the renin-angiotensin system in the development of abdominal aortic aneurysms in animals and humans. Ann N Y Acad Sci 2006;1085:82-91.

23. Ahimastos AA, Aggarwal A, D'Orsa $\mathrm{KM}$, et al. Effect of perindopril on large artery stiffness and aortic root diameter in patients with Marfan syndrome: a randomized controlled trial. JAMA 2007;298: 1539-47.

24. Lacro RV, Dietz HC, Wruck LM, et al. Rationale and design of a randomized clinical trial of $\beta$-blocker therapy (atenolol) versus angiotensin II receptor blocker therapy (losartan) in individuals with Marfan syndrome. Am Heart J 2007;154: 624-31.

25. Pediatric Heart Network. Marfan study basics. (Accessed June 2, 2008, at http://www.pediatricheartnetwork.org/ marfanforhealthcareproviders.asp.)

Copyright (c) 2008 Massachusetts Medical Society.

\section{JOURNAL EDITORIAL FELLOW}

The Journal's editorial office invites applications for a one-year research fellowship beginning in July 2009 from individuals at any stage of training. The editorial fellow will work on Journal projects and will participate in the day-to-day editorial activities of the Journal

but is expected in addition to have his or her own independent

projects. Please send curriculum vitae and research interests

to the Editor-in-Chief, 10 Shattuck St., Boston, MA 02115

(fax, 617-739-9864), by September 30, 2008. 